\title{
Theorizing international inequalities in communication and media studies. A field theory approach
}

KOME - An International Journal of Pure Communication Inquiry Volume 6 Issue 2, p. 92-110. (C) The Author(s) 2018 Reprints and Permission: kome@komejournal.com Published by the Hungarian Communication Studies Association DOI: 10.17646/KOME.75692.94

\section{Marton Demeter ${ }^{1}$}

\section{${ }^{1}$ Károli Gáspár University of the Reformed Church in Hungary, HUNGARY}

\begin{abstract}
In this paper we theoretically interpret empirical results regarding academic habits in communication and media studies. The theoretical framework used is Bourdieu's frame theory throughout the analysis. The purpose of this effort is twofold. First, we argue that the Bourdieusian theory is an adequate theoretical frame for explaining existing data on academic performance and especially on international inequalities in communication and media studies. Second, we will make attempt towards a synthetized theoretical exposition of field theory by connecting main concepts and demonstrate dynamical interactions between them.
\end{abstract}

Keywords: field theory, communication and media studies, de-Westernization, Pierre Bourdieu, academic capital

\section{Introduction}

The history of communication and media studies (CMS) is rife with arguments for and against one of the most salient features of the discipline: its obvious Euro-America centrism. Lots of empirical research have conducted to investigate the measure of this Global North and South bias in the field in CMS: most of them deals with the publication output and the citation scores of different world regions (Demeter, 2017, 2018a; Freelon, 2013; Lauf, 2005; Waisbord, 2015a; Waisbord, 2015b; Wang, 2014). Most researchers consider North America, Oceania, Western Europe and the developed Asia (Japan, Korea, Taiwan, Singapore and Hong Kong) as parts of the Global North, and South America, the developing Asia, Africa, the Middle East as parts of the Global South. Eastern Europe has a specific place since it is either considered as part of the Global North (Lauf, 2005) or the Global South (Author, 2018b; Heilbron et al., 2018) and there also are researchers that not even mention this part of the world (Hallin and Mancini, 2005). Based on the recognition that in terms of its history, its economic features and its marginal political position Eastern Europe has much more in common with other parts of the Global South than those of the Global North, we consider Eastern Europe as part of the former.

While we have great bulks of empirical research on this topic, academics in CMS somehow failed to produce a detailed and convincing theory that could explain the dynamics of the processes that leads to the international bias against the Global South. In this current paper we use the Bourdieusian field theory (Bourdieu, 1988; 1998; 2004) to frame the field of Address for Correspondence: Marton Demeter, email: mail.demeter.marton[at]gmail.com Article received on the 24th August, 2018. Article accepted on the 04th December, 2018. Acknowledgements: This paper was supported by the János Bolyai Research Scholarship of the Hungarian Academy of Sciences.

Conflict of Interest: The author is the co-EiC of KOME. 
CMS: we will examine the field-controlling norms (Rothenberger et al., 2017), the habitus of communication scholars and their academic capital that has been collected during their career. Since we would like to provide a coherent picture of the field of CMS, we will not just interpret the most important Bourdieusian concepts through this particularly discipline, but we also connecting and cross-referring the main analytical terms with each other. As a result, we will get a synthetized theory on communication, as a unique academic field with its special types of preferred habitus, norms and capital. We have to emphasize the interpretative nature of our analysis since we haven't attempt to simply summarize or recite the orthodox Bourdieusian theory but we rather consider the basic concepts of field theory as tools that could be used flexibly.

\section{Global North - Global South bias in the field of CMS}

Analyzing publication patterns in CMS dates back as early as 1989, when Communication Research published its special issue (Vol 16 Issue 4) dedicated to this topic. Later analyses on publication patterns dealt with citation networks in CMS journals (Borgman, 1989; Borgman and Reeves, 1983; Bunz, 2005; Feeley, 2008; Funkhouser, 1996; Rice, Borgman and Reeves, 1988; Rogers, 1999). In terms of publication inequalities, the most important papers were published in 2005, in which Edmund Lauf analyzed the international diversity of 40 SSCI journals in CMS, and in 2018, when (Demeter, 2018a) analyzed the national diversity of communication journals in Scopus. Both research found a very low level of internationality with an overwhelming American predomination. The second best performing region was Western Europe, followed by the developed parts of Asia. The contribution of the Global South (including Africa, South America, the developing Asia, the Middle East and Eastern Europe) was almost unnoticeable. Lauf (2005) found the same bias in terms of editorial board membership of leading journals in CMS: beside the overrepresentation of the US and some Western countries, the contribution of the Global South was minimal or even totally absent.

Former research already tried to find at least partial explanations for the phenomenon of the Global North's overrepresentation in CMS. The first type of explanations suggests that beside cultural, linguistic and epistemic factors, the economic indicators of world regions plays critical role in their international publication output. For example, correlations between the GDP, per capita GDP and the publication success of a given region were find in some empirical research (Demeter, 2018a; Lauf, 2005). In short, economic explanations state that economic well-being of a given country determines, at least partly, the publication success of a CMS scholar working in that country. The second type of explanations deals with the historical facts behind the field of CMS (Pooley and Park, 2013; Simonson et al., 2013; Waisbord and Mellado, 2014.) The so-called "received history" of the field (Pooley and Park, 2013) tells us that the discipline begins with the study of propaganda in the US, and all the four "founders of communication studies", namely Kurt Lewin, Carl Hovland, Harold Lasswell and Lazarsfeld were American, at least in terms of their education. The same authors also point out that most historians of CMS simply ignored the Global South, and this could be conceived as a patterned neglect of non-Western scholarship. In terms of academic institutionalization, the EuroAmerican precedency is also obvious: the first university-based communication education (mostly in journalism) were established in American, German and French universities in the first years of the 20th century. It was also in the US where "communication was first institutionalized as an academic field in the decades after World War II" (Simonson et al., 2013, p. 26). Finally, we have a political-historical explanation (Lauk, 2015) that deals with the fact that in most parts of the Global South there was a repressive political regime for decades that made the development of CMS literally impossible. The typical example is the state socialism of all Eastern European and some Asian, South American and African countries. In other 
counties, there were, and in some cases, there is still military or religious dictatorship. The serious deficiencies in free speech, the absence of press freedom, the prohibition of international traveling and the lack of appropriate language learning led to isolation from the international scientific community especially in the case of the ideologically more sensitive social sciences (Kornai, 1992).

\section{The field of forces in the Bourdieusian theory and in CMS}

Bourdieu conducted heroic efforts to emphasize the role that the field of forces plays in academic life, and his later followers dedicated an enormous amount of research to this topic (Bauder, 2015; Bauder et al., 2017; Grenfell, 2008; Gouanvic, 2005; Hilgers and Mangez, 2015; Leung, 2013; Recke, 2011; Rothenberger et al., 2017; Thatcher et al., 2016; Wacquant, 2018; Wiedemann and Meyen, 2016). According to the original Bourdieusian idea, the field is "the space of the relations of force between the different kinds of capital or, more precisely, between the agents who possess a sufficient amount of one of the different kinds of capital to be in a position to dominate the corresponding field" (Bourdieu, 1988, p. 34). The field of forces (the original le champ is sometimes translated as field of power or simply force field) has the well-established institutions of the Kuhnian normal science which entails the ruling academic language and rhetoric (Oshima-Hogue, 1999; Liu et al., 2018), high valued affiliations like world class universities and research institutions (Neuman etl al, 2008), leading journals, main publishers, selection committee memberships, administrative positions (Asheulova and Dushina, 2014) or university rankings (Pietrucha, 2018). Therefore, the field of forces consists of many subfields or institutions (Fig. 1) that are tightly interwoven with each other in various ways. 
Figure 1. The constituents of the field of forces

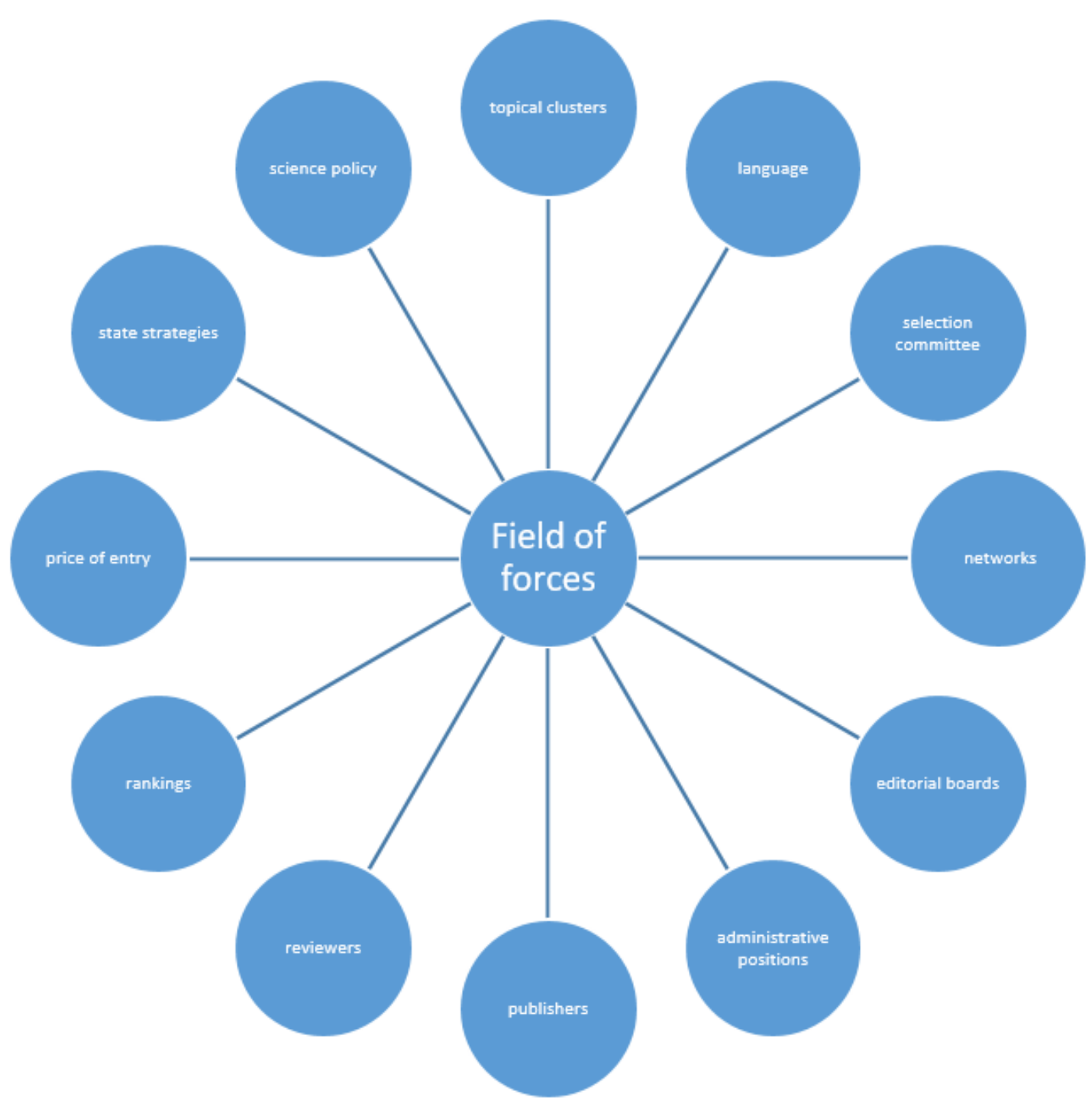

Each subfield of the field of forces holds possession of some institutional power. Selection committees can decide the career paths of individual researchers by prescribing the price of entry (Bourdieu, 2004) and the tenure conditions. Earlier in their career, international communication scholars should publish at least one or two papers in leading periodicals, preferably in ICA or NCA journals for a successful tenure application proposed to any acknowledged institution (Pooley, 2015). Because of their almost absolute power in determining career possibilities of young researchers, selection committees play the role of gatekeepers to the field of forces. The earlier mentioned international scientific communities like ICA, NCA or IAMCR play serious roles in the field of forces of CMS, and the bias against Global South authors is well known in case of all these associations (Wiedemann and Mayen, 2016; Zelizer, 2015). Another important factor of the field of forces is language, more precisely, the academic English of the international community of CMS scholars. As both Lauf (2005) and (Demeter, 2018a) puts it, leading periodicals in CMS publish English content exclusively. Even if being published, non-English articles suffer from lower citation scores than English papers (Liu et al., 2018). It is obvious then, that this fact results in serious bias against non-English authors since they should learn a second language on a professional level as an 
extra investment, and they presumably read and write slower than their native English peers (Horn, 2017). Moreover, beside the language itself, they should also master the Anglo-Saxon rhetoric and academic writing skills (Oshima and Hogue, 1999). Beside language and selection criteria, the field of forces also determines the preferred thematic clusters (Freelon, 2013; Günther and Domahidi, 2017; Neuman et al., 2008). Empirical research show that in CMS, some orthodox topics of research are preferred, typically those of with American focus, and research conducted with quantitative social science methods is easier to publish than those of written on non-Western topics and conducted by non-mainstream approaches. The characteristic clusters in CMS are interpersonal communication, race and media, parasocial interaction, multimedia, political communication, hostile media, psychology of communication and agenda setting Freelon, 2013). Moreover, all these clusters have their "citation universes" and received methodologies. In order to being published, most early career scholars tend to achieve their research in the orthodox thematic clusters, with the orthodox methods and based on the orthodox literature. Science policy and state strategies works on the macro-level and their effects on the field of forces raises with the decline of the relative autonomy of the sciences. When the state abandons the sciences by cutting their funding, as it has been happened in the case of Russia and many other Eastern European regions, the most talented researchers will try to move towards more prosperous regions. The opposite is true when the state deliberately invests in academic institutions and research programs, like in China, because it results in strengthened academic life (Asheulova and Dushina, 2014). University rankings and journal rankings like Scopus or SSCI play also important role in organizing the field of forces, since international students and the most mobile international scholars will target the top ranked universities (Pietrucha, 2018). In the case of Shanghai Ranking, research output is one of the most important categories with extraordinary emphasis on SSCI papers. Other rankings like the QS World University Ranking or The Times Higher Education World University Ranking also calculate with the publication output of the employees. Lecturing at the top ranked universities and publishing in the top ranked periodicals results in prestige and a great amount of academic capital. Finally, besides selection committee members, publishers, editorial board members and reviewers also play the role of gatekeepers in the field of forces, since they could determine the publication output of international researchers. We have 293 Scopus-indexed and 79 SSCI indexed periodicals in CMS (in 2017). Most Scopus-indexed and all SSCI indexed journals are published in the Global North (Demeter, 2018a, 2018b), and most editorial boards consist of Global North editorial board members (Lauf, 2005). It means that the field of forces is strongly biased against Global South authors from these respects, too.

\section{The habitus, the norms and collecting academic capital in CMS}

Habitus is one of the main concepts of Bourdieu's field theory, and it refers to some durable and transposable dispositions or tendencies social agents have in order to being active during social actions (Grenfell, 2008). Regarding habitus in practice, the most important empirical phenomenon in career development is the mobility of researchers, because it effects on other parts of the habitus like publication habits (Aksnes et al., 2013), proper conduct (Rothenberger et al., 2017), cooperation skills (Henriksen, 2018; Ronda-Pupo and Katz, 2018) or networking (Bormann, 2017; Coccia and Bozemann, 2016). 
Figure 2. The constituents of habitus

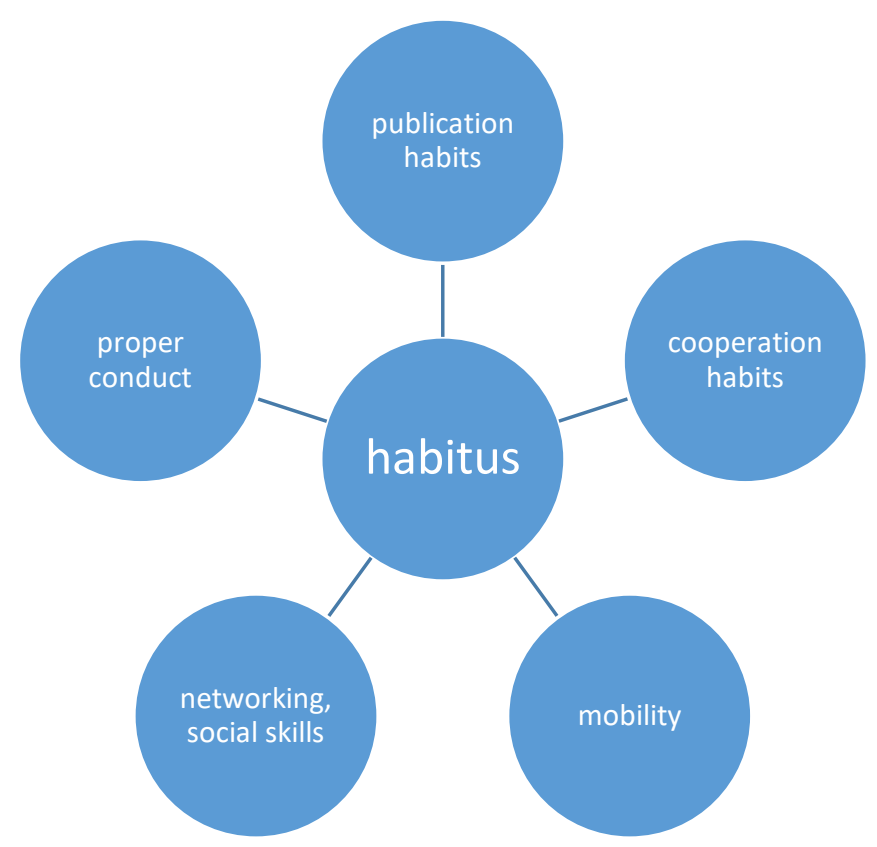

The general rule of mobility is that talent often flows from the Global South to the core as scholars seek out employment in recognized institutions of higher learning in the Global North (Lee and Kuzhabekova, 2017). Mobility, that is, being educated or work abroad raises the symbolic or academic capital of researchers in a great extent, while immobility often results in narrowed career paths. The motivations between mobility include simply economic features like higher salary or better material-technical conditions, but research show that the promotion of scientific visibility - growth in publication output, coauthored international publications or the increase of citation indices - also play very important role (Asheulova and Dushina, 2014; Aksnes et al., 2013). Moreover, internalization, that is, the concept of a neoliberal and global university (Herschberg et al., 2018) became a keyword or norm that most universities should strive for. Mobility as a habitus, therefore, became not just an important source of academic capital for individual researchers, but a valuable feature that international universities support and appreciate as well. For mobility is the most important factor when Global South academics wish to raise their academic capital, it is expected that more mobile authors will collect more capital. Amongst the most obvious examples of "entry level" (Bourdieu, 2004) academic capital like BA, MA or PhD degrees accomplished in the Global North, scientists could collect advanced types of capital in the form of Global North postdoctoral research experience, international grants, Global North affiliations (Shen et al., 2018) and, mostly, publications in leading periodicals (Cole, 1967; Hanssen et al., 2017). Networking, collaboration and coauthorship are also sources of measurable academic capital in terms of both citation and publication output (Bormann, 2017; Coccia and Bozemann, 2016; Henriksen, 2018; Katz, 1999; Ronda-Pupo and Katz, 2018).

The role of norms in the Bourdieusian theory was extensively investigated by Rothenberger et al. (2017), but we should still relate them directly to the field of CMS (Fig. 3). 
Figure 3. The constituents of norms

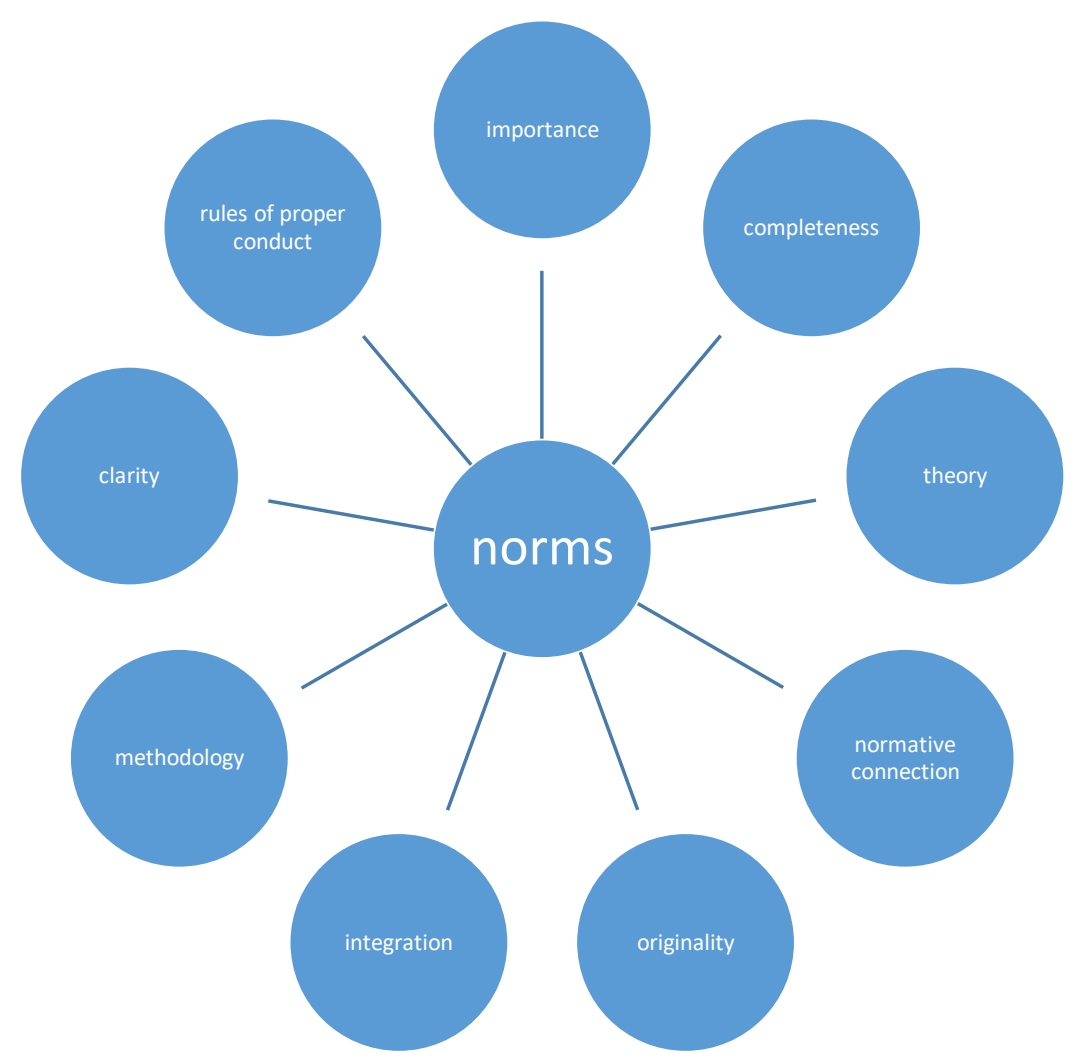

Following Neuman et al. (2008) we could state that there are a bunch of norms that play crucial role in assessing a communication scholar's work. We have norms like importance, theoretical integration, methodology, completeness, normative connection and originality. Based on their extensive analysis on peer review decisions the authors find that the most important norms are clarity (of the research paper), methodology and theoretical integration, while importance, originality and normative connection turned out to be marginal as selection criteria which means that, in most cases, reviewers wrote that the paper was important and original. According to their research, however, the most important norms are related to the theory used:

"we have thus far come to the conclusion that theory is king. Without a clear connection to an identifiable theoretical corpus and providing an original contribution to that corpus, pristine prose or magnificent methods do not provide the key to scholarly recognition." (Neuman et al., 2008, p. 230)

These underlying norms determinate the prospect of scientists to publish their articles in prestigious journals since, in order to being published, they should be familiar with basal norms. In a less extent, the opposite could also be true, for scientific communities could affect serious methodological or epistemic change (Estrade, Hernandez and Schulz, 2018). It is noteworthy that publishing in leading periodicals is not an optional but a necessary assignment when a researcher plans an international career, for the most important condition for professional success represented in tenure and hiring decisions is based on publications in leading peerreviewed journals (King et al., 2017; Zdenek, 2017). Since most norms are learned through education, and leading journals are published exclusively at the Global North, authors educated in the Global South face significant challenges when trying to publish their research in the most prestigious periodicals (Lauf, 2005). Acquiring and adopt these norms through being mobile 
and have Global North education is, therefore, essential to a successful research career (Meyen, 2012; Wiedemann and Meyen 2016). In other words, especially for those academics from the Global South, mobility turned out to be the most effective habitus to collect capital.

Bourdieu's notion of capital could be roughly conceived as the extension of the economic sense of the concept, since Bourdieu's purpose is to extend the sense of the term "capital" by employing it in a wider system of exchanges whereby assets of different kinds are transformed and exchanged within complex networks or circuits within and across different fields. He is attempting to relocate the narrow instance of mercantile exchange away from economics into a wider anthropology of cultural exchanges and valuations of which the economic is only one (though the most fundamental) type. It is important to note, however, that other forms of capital such as cultural and social can be seen as "transubstantiated" forms of economic capital. (Grenfell, 2008, p. 102).

On the basis of the literature of Bourdieusian theory we could distinguish four kinds of capital (Fig. 4).

\section{Figure 4. The constituents of capital}

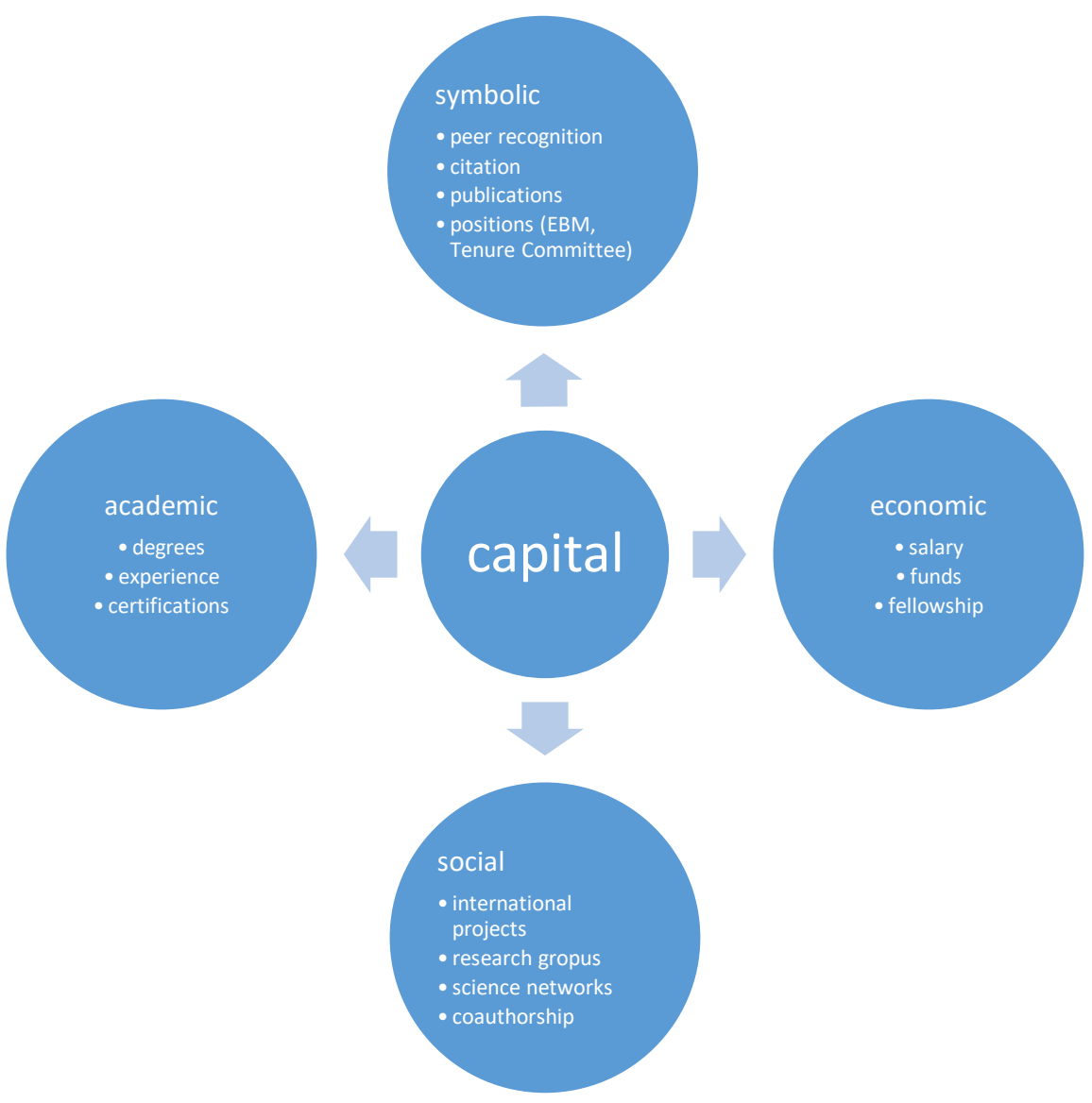

The first and most obvious category is the academic capital that could be accumulated in the form of certifications, degrees, fellowships, research grants and work experience. Academic capital that has been collected in the top of the hierarchy (typically, in the US and other Englishspeaking countries) is much more valuable than those of collected in rather peripheral countries (Bauder, 2015; Bauder et al., 2017). Another type of capital is the social capital, which consists of demonstrable records of participating in international collaborations, research groups and 
science networks, like ICA and NCA in the case of CMS. Also, a quite impressive demonstration of the social capital of individual researchers is the number of their international coauthored papers (Bormann, 2017; Ronda-Pupo and Katz. 2018). Research shows that the increase of social capital in the form of coauthored papers also effects increased citation scores (Henriksen, 2018). Again, since the field of CMS is fairly hierarchical and biased towards EuroAmerican institutions (publishers, journals, universities and affiliations), researchers from the Global South try to cooperate strategically with Global North authors. By contrast, Global North authors cooperate, mostly, with each other, and their cooperation with Global South authors is rather idiosyncratic (Demeter, 2017). The third type of capital is the economic capital, and research shows that this is one of the main factors behind labor migration towards the Global North (Asheulova and Dushina, 2014). Economic capital typically consists of factors like salary, the level of material-technical conditions for scientific activities and the accessibility of external funds. The relatively low level of economic capital tends to effect serious damages on the career trajectory of Global South researchers since they frequently have to undertake other duties beside their academic work and this "divided or parallel career path" often results in leaving academy. Finally, the fourth type of capital is the symbolic capital in the widest sense, which consists of many forms and aspects of contemporary recognition. But this is not only a matter of vanity, since symbolic capital could be easily transferred to economic capital. For example, one of the most important manifestations of symbolic capital is the number of one's citations, which is a very strong trump-card in a job interview or in the course of an academic promotion. Other types of symbolic capital are hierarchical positions in tenure committees or in editorial boards of prestigious journals. In these cases, the capital consists of the power of one individual to give or deny capital to and from other agents on the field. Finally, the number of publications in prestigious journals should be conceived as symbolic capital which, similarly to the citations scores, could be transferred to economic capital through promotion. Furthermore, some institutions premiate the publication of SSCI indexed articles even financially.

\section{The field of struggle in CMS: heterodox and orthodox scholars}

The field of struggle is the "place" where scientific revolutions start to develop by the nonconformist activity of heterodox scholars (Bourdieu, 2004). As in the case of any sciences, we can differentiate between push and pull activities in CMS: while the former involves the (mostly critical) activities of yet peripheral "heterodox" scholars, the latter relates to the (mostly conservative) activities of more central "orthodox" agents. Heterodox scholars, therefore, frequently criticize the publication bias towards Global South authors. Typical theoretical frameworks for explaining the phenomenon of scientific inequalities are dependency theory (Ferraro, 2008; Prebisch, 1959; Thomas-Slayter, 2003) and Matthew Effect, especially the theory of the Matthew Effect for Countries (Bonitz, Bruckner and Scharnhorst, 1997). Dependency theories had been invented as a reaction to the popular Modernization Theory of the first half of the 20th century. The first class of dependency theories dates back to Prebisch (1959), who has a Marxist conception on the global economic system. His most important statements were that 1 ) the center derived (at least partly) its wealth from the periphery 2) the relationship between subdominant and dominant states is an enduring one and 3) the only chance for a dependent area to become a center is that it should break away from the old, dominant center (Love, 1980). As an addition to the existing bias towards Global South authors, we have the Matthew Effect for Countries that says even Global South authors may succeed in publishing their work in leading journals, they will be less cited that their developed country colleagues: A minority of countries, expecting a high number of citations per scientific paper, gains more citations than expected, while the majority of countries, expecting only a low 
number of citations per scientific paper, achieves fewer citations than expected. In the spirit of Merton we called this effect Matthew Effect for Countries (Bonitz, Bruckner and Scharnhorst 1997, 408). Authors from different regions of the Global South investigated the nature and possible causes of these inequalities. There are profound analyses on this topic from South America (Jalata, 1993; Perez, 1990), from Africa (Amadi, 2012; Onyancha, 2016), from Asia (Hung, 2016; Myrdal, 1974; Yutisri, 2016) and from Eastern Europe as well (Bruszt and Gerkovits, 2009; Bruszt and Langbein, 2017; Demeter, 2018b). But with the so-called deWesternization theories of some Global North scholars the "pull effect" also started to play on the field of struggles in CMS (Rothenberger et al., 2015; Waisbord, 2015a; Waisbord, 2015b; Waisbord and Mellado, 2014; Wang, 2014). De-Westernization means, at least theoretically, the critic of West-centrism of the field: "The critique of Euro-American centrism in communication theories has in recent years led to calls for Afrocentric/Asiacentric approaches to research, and the emergence of geocultural theories. The discussion has underscored the urgency for us to re-examine the way cultural differences are handled in academic discourse". (Wang 2014,373). According to Waisbord and Mellado (2014), de-Westernization should be related to scholars, topics, themes, ideas, methods, experiences, epistemologies, theoretical perspectives and academic cultures. Sivlio Waisbord, current editor of ICAs flagship Journal of Communication clearly expresses his conception regarding de-Westernization in his $2015 \mathrm{~s}$ editorial: "JoC also needs to reflect the globalization of ICA and the field of communication. [...] It needs to give visibility to arguments that invite us to rethink conclusions largely drawn from studies conducted in the United States and a few countries in the West. JoC needs to be embedded in the globalized academia to enrich analytical perspectives, broaden research horizons, and connect diverse academic cultures of communication scholarship". (Waisbord 2015a, 586-587). Notwithstanding, if we take a look on the national diversity of Journal of Communication's publication output before and after the above discussed de-Westernization plans we could not find any significant changes in this respect (Table 1).

Table 1. World regions' contribution in Journal of Communication in the period 2013-2014

\begin{tabular}{|c|c|c|c|c|c|c|}
\hline \multicolumn{7}{|c|}{ and between 2016-2017 } \\
\hline Global North & South America & Asia & Eastern Europe & Africa & Middle East & \\
\hline \multicolumn{7}{|l|}{ 2016-2017 } \\
\hline US & 59 Chile & 3 China & 2 Poland & 1 South Africa & 1 Turkey & 1 \\
\hline UK & 12 Mexico & 2 Singapore & 2 & & & \\
\hline Germany & 11 Colombia & 1 Hong Kong & 1 & & & \\
\hline Netherlands & 8 & Philippines & 1 & & & \\
\hline Israel & 6 & & & & & \\
\hline Australia & 4 & & & & & \\
\hline Austria & 4 & & & & & \\
\hline Spain & 4 & & & & & \\
\hline Belgium & 3 & & & & & \\
\hline Finland & 2 & & & & & \\
\hline Switzerland & 2 & & & & & \\
\hline Canada & 1 & & & & & \\
\hline Iceland & 1 & & & & & \\
\hline Norway & 1 & & & & & \\
\hline \multirow[t]{2}{*}{ Sweden } & 1 & & & & & \\
\hline & 119 & 6 & 6 & 1 & 1 & 1 \\
\hline \multicolumn{7}{|l|}{ 2013-2014 } \\
\hline US & 80 Chile & 2 Korea & 3 & & & \\
\hline Germany & 12 & China & 2 & & & \\
\hline Netherlands & 9 & Singapore & 2 & & & \\
\hline Austria & 3 & Hong Kong & 1 & & & \\
\hline Switzerland & 3 & Taiwan & 1 & & & \\
\hline Australia & 2 & & & & & \\
\hline Belgium & 2 & & & & & \\
\hline Israel & 2 & & & & & \\
\hline Italy & 2 & & & & & \\
\hline Denmark & 1 & & & & & \\
\hline \multirow[t]{2}{*}{ UK } & 1 & & & & & \\
\hline & 117 & 2 & 9 & $\mathbf{0}$ & $\mathbf{0}$ & $\underline{0}$ \\
\hline
\end{tabular}


Data show that the contribution of the Global North is around 90 percent in both time periods, and the Global South failed to raise its publication output. The contribution of the US has been slightly decreased but mostly in favor of other Global North regions, typically Western European countries and not for the benefit of Global South authors. The inequality between different regions of the Global South still holds: the developing Asia (mostly China) and South America have certain contribution in CMS, the participation of other regions like the Middle East, Africa and Eastern Europe was and is still absolutely unnoticeable. We have to admit, however, that since we do not have data on submitted but only on published articles, we could not tell whether this low contribution of the Global South is due to the lack of submissions or the result of high reject ratios towards authors from this region. Nevertheless, even if we could not ascertain the exact causes yet, we could still draw the conclusion that de-Westernization aspirations of the center couldn't raise the contribution of the Global South at this time.

We have just presented a very narrow research that shows de-Westernization is far from being achieved in CMS. Since in this rather theoretical article we do not concentrate on conducting diversified empirical research, we could just refer to other, more empirical studies that show the same strong bias against Global South papers in terms of publication output (Demeter, 2018a; Freelon, 2013; Lauf, 2005; Waisbord, 2015a; Waisbord, 2015b; Wang, 2014).

Beside leading periodicals like the above mentioned Journal of Communication, international academic associations also recognized the importance of de-Westernization (Meyen, 2012; Wiedemann and Meyen, 2016; Zelizer, 2015). Nevertheless, their research show that most fellows of the ICA has exclusively American background, and all fellows has very strong, typically educational relations to the Global North. It seems from data that it is almost impossible to became an internationally recognized scholar in CMS without a massive measure of Global North capital.

Today, ICA's international leadership is located in world regions closely linked to the United States and educated at U.S. universities or heavily influenced by North American research traditions, even if it includes a numerous contributions from other associations and alternative approaches [...].National academic environments in U.S.-affiliated countries became Americanized, especially via ICA fellows serving as role models to get scientific capital. Thus, ICA's efforts to expand its leadership are assumed to have an unintended effect of conserving the power structures in the field. (Wiedemann and Meyen, 2016, p. 1489).

It is noteworthy, that Wiedemann and Meyen deals with mostly de-Americanization that means they consider non-American ICA fellows' career paths and found that they have strong and manifold relations to the US. But from their data we could abstract an even more striking fact, namely, that there are no Global South scholars amongst ICA fellows, former and future presidents at all. From the 112 distinguished ICA fellows there are 86 from the US, followed by Germany (4), the UK (3), Canada (3), Israel (3), Australia (2), the Netherlands (2), Singapore (2), and we have 1-1 fellows from Belgium, Denmark, Sweden, Finland, South Korea, Japan and Hong-Kong. As the authors accurately observed, "for ICA going international means going to rich, economically strong countries." (Wiedemann and Meyen, 2016, p. 1496). As a conclusion we can say that center-based pull-efforts or de-Westernization attempts in the field of struggle haven't succeed in raising the contribution of the Global South in CMS. There is no significant accession in the number of Global South articles in leading CMS periodicals, and the participation of Global South fellows in most prestigious academic associations is totally unnoticeable. 


\section{An attempt to synthesize Bourdieusian concepts}

Although the use of Bourdieusian concepts is quote common amongst social scientists, specialists often argue that sometimes it is hard to find satisfactory agreement regarding the correct sense of the original notions (Grenfell, 2008; Shusterman, 1999; Thatcher et al., 2016). The cause of this ambiguity is likely the fact that Bourdieusian concepts tend to define each other mutually, so the linear exposition of his field theory is rather hard to develop. Therefore, we chose a network style exposition for our attempt to synthesize field theory and its main concepts, therefore all the main concepts will be related to each other (Fig. 5).

Figure 5. The synthesized network of field theory's main concepts

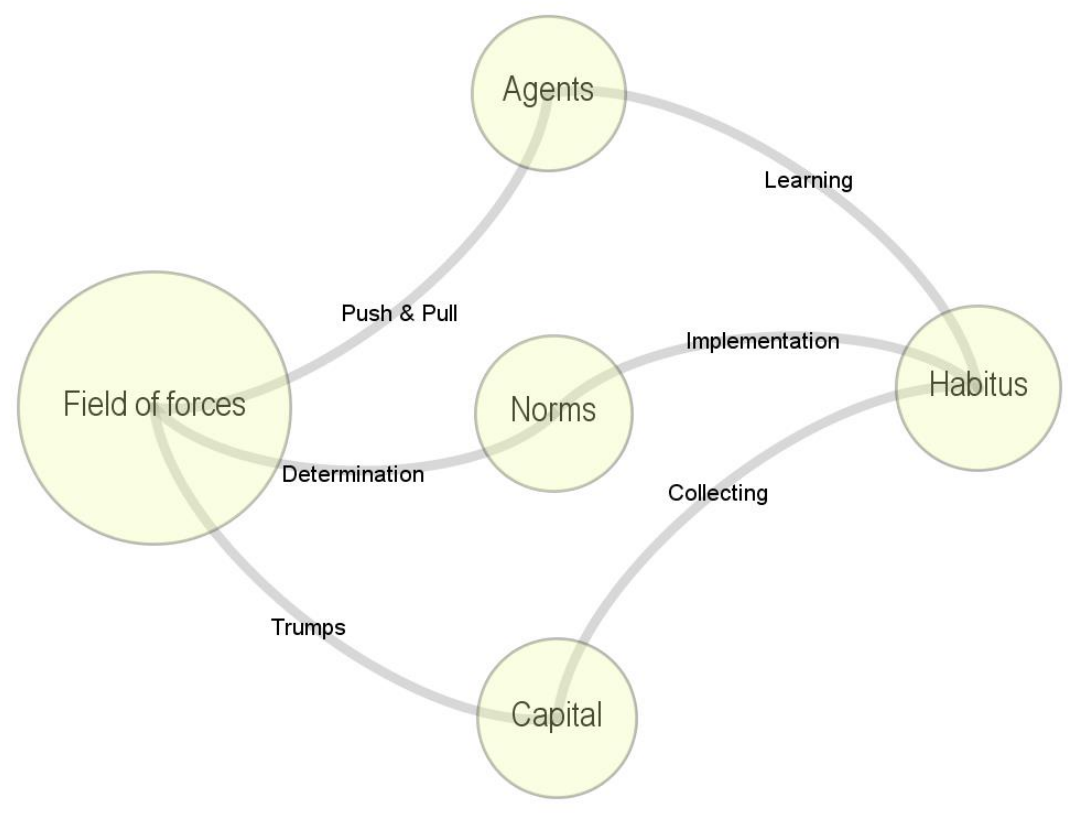

In our understanding, there is no central concept in field theory; instead we have four central concepts (habitus, capital, field and norm) plus an additional one, namely, the agent who acts in the social field. Thus we will start our exposition with the agents that could be individual, collective or institutional. On an individual agent we mean individual researchers with appropriate capital for acting successfully on the field by certain norms. If the agent's performance is successful at a given field, then that agent has the fitting habitus. But as individual agents collect individual capital (in the form of citations, for example), collective and institutional agents save collective or institutional capital. Examples for collective agents are research teams and laboratories, while universities, disciplines, countries and world regions and even science in itself could be conceived as institutional agents. For not just the individual researchers but also research teams and whole regions (even as great ones as the Global South itself) strive for being represented in the map of international science, they tend to accumulate capital collectively. The strife or field of struggle where science as a whole competes is slightly different from the situations where the competition runs inside the field of science: here science 
competes with other social institutions like health care, culture or sports for a finite amount of state or public fund.

Just like as capital could be collected individually or collectively, habitus could be internalized by either an individual or a collective agent. Since a habitus is always the habitus of an (individual or collective) agent, the concept of the former could not be conceived without the latter. It is always the (physical, cognitive, affective, ethical or institutional) structure of a given agent that support (or prohibit) the development of a given habitus and the whole process, namely, the internalization of the habitus happens on and by the rules of the field of forces. In return, the field of forces consists of, basically, individual and collective agents which play different power roles on the same field. While agents' habitus could be modified by the field of forces via different pull and push effects, norms are much more resistant to change since they are originated and usually institutionalized in the field of forces. In other words, norms control the field of forces while habitus control the behavior of the agents. The function and dynamics of norms on the level of the field is quite similar to the function and dynamics of habitus on the level of the individual or collective agents. Just like agents (of a given field) could be conceived as embodied fields of forces (Bourdieu, 2004) we can say that habitus is the individualized and agent-specific realization of ruling norms.

As it is represented on Fig. 5, we could draw a synthesized network of field theory's main concepts. Since this network should be conceived as a connected graph, we could start the interpretation from any concept. When we select, for example, the concept of agent, we will see its immediate connections with habitus via learning, and with the field of forces via push and pull effects. In other words, the main goal of agents is to get better positions at the field of forces while other agents on the field of forces determine the availability of every possible positions. Since agents could reach this goal by collecting academic capital, they have to learn the appropriate habitus by which it can be achieved as fast as it is possible. This collected capital serve as trumps on the field of forces: the more capital you have the more likely you will get top positions here. Norms, which are the most stable elements of the network control the field of forces by determining the rules of the academic competition on the one hand, and, on the other hand, they serve as models for the appropriate habitus that is the agent-specific implementation of ruling norms.

\section{Conclusions}

In this paper we aimed to contribute to the literature of communication theory in general, and to Bourdieusian field theory in particular in two ways.

First, we tried to show that the large quantity of information we have regarding Global North - Global South inequalities in communication and media studies needs to be interpreted in a coherent theoretical framework, and Bourdieu's frame theory proved to be adequate for this role. This is also the first study in which the empirically tested performance of CMS's field of forces was discussed theoretically. In other words, we could theoretically interpret data from former empirical research and, at the same time, we could corroborate field theory through connecting data to the appropriate theoretical concepts of field theory.

Second, we tried to synthetize the main concepts of Bourdieu's field theory to show their relatedness. Our conceptual analysis shown that the linear development of the theory might be extremely hard and even confusing since all the main concepts define each other, so we chose to use a network style exposition. Our attempt to synthetize the theory's basic concepts resulted in a network of concepts in which the connections between the main elements are easy to follow.

Communication scholars - similarly to their peers in other disciplines - tend to function in an unreflective way. Norms, and through norms, habitus are internalized by culture, role 
models and education unconsciously. The fact that communication scholars collect academic capital to get better positions at the field of forces could be obscured by popular narratives on the purity and unselfishness of science: that's why Bourdieu wrote that we should not listen to just what scientist say but what they actually do (Bourdieu, 2004). Through the norms which control the field of forces many one-sided practices fixate, and it results in serious biases against agents outside the field of forces. In spite of the fact that the so-called de-Westernization attempts strive to reduce Global North - Global South inequalities we could not see significant changes yet. Accordingly, being familiar with the operations in the field of forces in CMS might be very useful for not just those peripheral scholars who want to raise their prospects but for all those agents at the Global North who strive for a more equal and unbiased field of forces in CMS.

\section{References}

Aksnes, D.W., Rorstad, K., Piro, F.N. \& Siversten, G. (2013). Are mobile researchers more productive and cited than non-mobile researchers? A large-scale study of Norwegian scientists. Research Evaluation, 22(4), 215-223. CrossRef

Amadi, L. (2012). Africa: Beyond the "new" dependency: A political economy. African Journal of Political Science and International Relations 6(8), 191-203. CrossRef

Asheulova, N. \& Dushina, S. (2014). Research career development in Russia: the role of international mobility In: Weijden, I. \& N. Asheulova, N. (2014). (Re)searching scientific careers. St Petersburg: Nestor-Historia, 171-196.

Bauder H. 2015. The international migration of academics: a labour market perspective. International Migration, 53, 83-96. CrossRef

Bauder, H., Hannah, C.A. \& Lujan, U. (2017). International Experience in the Academic Field: Knowledge Production, Symbolic Capital, and Mobility Fetishism. Population, Space and Place, 23, 1-13. $\underline{\text { CrossRef }}$

Bonitz, M., Bruckner, E. \& Scharnhorst, A. (1999). The Matthew-index. Concentration patterns and Matthew journals. Scientometrics, 44(3), 361-378. CrossRef

Borgman, C.L (1989). Bibliometrics and scholarly communication. Communication Research, 16(5), 583-599. CrossRef

Borgman, C.L. \& Reeves, B. (1983). A bibliometric evaluation of core journals in communication research. Human Communication Research, 10(1), 119-136. CrossRef

Bornmann, L. (2017). Is collaboration among scientists related to the citation impact of papers because their quality increases with collaboration? An analysis based on data from F1000Prime and normalized citation scores. Journal of the Association for Information Science and Technology, 68(4), 1036-1047. CrossRef

Bourdieu, P. (1988). Homo Academicus. Stanford: Stanford University Press. 
Bourdieu, P. (1998). Practical Reason. On the Theory of Action. Stanford: Stanford University Press.

Bourdieu, P. (2004). Science of Science and Reflexivity. Cambridge: Polity Press.

Bruszt, L. \& Greskovits, B. (2009). Transnationalization, social integration, and capitalist diversity in the East and the South. Studies in Comparative International Development, 44, 411-434. $\underline{\text { CrossRef }}$

Bruszt, L. \& Langbein, J. (2017). Varieties of dis-embedded liberalism. EU Integration strategies in the Eastern peripheries of Europe. Journal of European Public Policy 27(2), 297-315. CrossRef

Bühlmann, F., Benz, P., Mach, A. \& Rossier, T. (2017). Mapping the power of law professors: The role of scientific and social capital. Minerva, 55, 509-531. $\underline{\text { CrossRef }}$

Bunz, U. (2005).Publish or perish: A limited author analysis of ICA and NCA journals. Journal of Communication, 55(4), 703-720. CrossRef

Cardoso, F.H. \& Faletto, E. (1979). Dependency and development in Latin America. Berkeley: University of California Press.

Coccia, M., \& Bozeman, B. (2016). Allometric models to measure and analyze the evolution of international research collaboration. Scientometrics, 108(3), 1065-1084. CrossRef

Cole, S. \& Cole, J.R. (1967). Scientific output and recognition: A study in the operation of the reward system in science. American Sociological Review, 32 (3), 377-390.

Demeter, M. (2017). The Core-Periphery Problem in Communication Research: A Network Analysis of Leading Publication. Publishing Research Quarterly 33(4), 402-421. $\underline{\text { CrossRef }}$

Demeter, M. (2018a). Changing Center and Stagnant Periphery in Communication and Media Studies. International Journal of Communication 12, 2893-2921. $\underline{\text { CrossRef }}$

Demeter, M. (2018b). The Winner Takes it All: International Inequality in Communication and Media Studies Today. Journalism and Mass Communication Quarterly (online first article, 2018). $\underline{\text { CrossRef }}$

Estrada, M., Hernandez, P.R. \& Schultz, P.W. (2018). A longitudinal study of how quality mentorship and research experience integrate underrepresented minorities into stem careers. CBE - Life Sciences Education 17, 1-13. CrossRef

Feeley, T.H (2008). A bibliometric analysis of communication journals from 2002 to 2005. Human Communication Researh, 34(3), 505-520. $\underline{\text { CrossRef }}$

Ferraro, V. (2008). Dependency theory: an introduction. In: Secondi, G. (2008). The Development Economics Reader. London: Routledge 
Freelon, D. (2013). Co-citation map of 9 comm journals, 2003-2013. Retrieved from http://dfreelon.org/2013/09/05/co-citation-map-of-9-comm-journals-2003-2013/

Funkhouser, E.T. (1996). The evaluative use of citation analysis for communication journals. Human Communication Research, 22(4), 563-574. CrossRef

Gouanvic, J.M (2005). A Bourdieusian theory of translation, or the coincidence of practical instances. The Translator, 11(2,) 147-166, CrossRef

Grenfell, M. (2008). Pierre Bourdieu. Key concepts. Stocksfield: Acumen Publishing.

Günther, E. \& Domahidi, E. (2017). What communication scholars write about: An analysis of 80 years of research in high-impact journals. International Journal of Communication, $11,3051-3071$.

Hallin, D.C. \& Mancini, P. (2004). Comparing media systems. Three models of media and politics. Cambridge: Cambridge University Press.

Hanssen, T.E.S, Jorgensen, F. \& Larsen, B. (2017). The relation between the quality of research, researchers' experience, and their academic environment. Scientometrics 114, 933-950. CrossRef

Heilbron, J., Sora, G. \& Boncourt, T. (2018). The social and human sciences in global power relations. London: Palgrave Macmillan.

Henriksen, D. (2018). What factors are associated with increasing co-authorship in the social sciences? A case study of Danish Economics and Political Science. Scientometrics 114, 1395-1421. CrossRef

Herschberg, C., Benschop, Y. \& Brink, M. van dem (2018). Selecting early-career researchers: the influence of discourses of internationalisation and excellence on formal and applied selection criteria in academia. Higher Education, online first article, $\underline{\text { CrossRef }}$

Hilgers, M. \& Mangez, E. (2015). Bourdieu's theory of social fields. Concepts and applications. New York, Routledge.

Horn, S. A. (2017). Non-English nativeness as stigma in academic settings. Academy of Management Learning \& Education, 16,(4), 579-602. CrossRef

Hung, N.M. (2016). Vietnam: Challenges and opportunities for publishers. Publishing Research Quarterly, 32, 266-271. CrossRef

Jalata, Asafa (2013). Colonial terrorism, global capitalism and African underdevelopment: 500 years of crimes against African peoples. The Journal of Pan African Studies, 5(9), 1-42.

Katz, J. S. (1999). The self-similar science system. Research Policy, 28(5), 501-517. CrossRef

King, M. M., Bergstrom, C.T., Correll, S. J. Jacquet, J. \& West, J.D. (2017). Men set their own cites high: gender and self-citation across fields and over time. Socius: Sociological Research for a Dynamic World, 3, 1-22. 
Kornai, J. (1992). The Socialist system. The political economy of communism. Oxford: Oxford University Press.

Lauf, E. (2005). National diversity of major international journals in the field of communication. Journal of Communication, 55(1), 19-151. CrossRef

Lauk, E. (2015). A View from the inside: The dawning of de-westernization of CEE media and communication research? Media and Communication, 3(4), 1-4. CrossRef

Lee, J.T. \& Kuzhabekova, A. (2017). Reverse flow in academic mobility from core to periphery: motivations of international faculty working in Kazakhstan. Higher Education, online first article. CrossRef

Leung, M.W,H. (2013). 'Read ten thousand books, walk ten thousand miles': geographical mobility and capital accumulation among Chinese scholars. Transactions of the Institute of British Geographers, 38(2), 311-324. $\underline{\text { CrossRef }}$

Leung, M.W.H. (2017). Social Mobility via academic mobility: reconfigurations in class and gender identities among Asian scholars in the global north. Journal of Ethnic and Migration Studies, 43(16), 2704-2719. CrossRef

Liu, F., Hu, G., Tang, L. \& Liu, W. (2018). The penalty of containing more non-English articles. Scientometrics, 114, 359-366. $\underline{\text { CrossRef }}$

Love, J.L. (1980). Raul Prebisch and the origins of the doctrine of unequal exchange. Latin American Research Review, 15(3), 45-72.

Meyen, M. (2012). International Communication Association fellows. International Journal of Communication, 6, 2378-2396.

Myrdal, G (1974). Against the stream. Critical essays on economics. London: Palgrave Macmillan.

Neuman, W. R., Davidson, R., Joo, S., Park, Y.J. \& Williams, A.E. (2008). The seven deadly sins of communication research. Journal of Communication, 58, 220-237. CrossRef

Onyancha, O.B. (2016). Open research data in sub-Saharan Africa: a bibliometric study using the data citation index. Publishing Research Quarterly, 32, 227-246. CrossRef

Oshima, A. \& Hogue, A. (1999). Writing Academic English. Third Edition. New York: Longman.

Park, D. W. (2014). Pierre Bourdieu. New York, NY: Peter Lang.

Perez, L.A. (1990). Dependency. The Journal of American History, 77(1), 133-142.

Pietrucha, J. (2018). Country-specific determinants of world university rankings Scientometrics, 114,1129-1139. $\underline{\text { CrossRef }}$ 
Pooley, J.D. \& Park, D.W. (2013). Communication research. In Simonson et al (2013). The handbook of communication history. London: Routledge, 76-93.

Recke, R. (2011). Converging principles of norm, rule, and practice: Tracing normativity beyond semantics in Bourdieu's outline of a theory of practice. Res cogitans, 2, 167-192.

Rice, R.E., Borgman C.L. \& Reeves, B. (1988). Citation networks of communication journals, 1977-1985 cliques and positions, citations made and citations received. Human Communication Research, 15(2), 256-283. CrossRef

Rogers, E.M. (1999). Anatomy of the two subdisciplines of communication study. Human Communication Research, 25(4), 618-631. CrossRef

Ronda-Pupo, G.A. \& Katz, J.S. (2018). The power law relationship between citation impact and multi-authorship patterns in articles in Information Science \& Library Science journals. Scientometrics 114, 919-932. CrossRef

Rothenberger, L.T., Auer, C. \& Pratt, C.B. (2017). Theoretical approaches to normativity in communication research. Communication Theory, 27, 176-201. CrossRef

Shen, S., Rousseau, R. \& Wang, D. (2018). Do papers with an institutional e-mail address receive more citations than those with a non-institutional one? Scientometrics, 115(2), 1139-1150. CrossRef

Shusterman, R. (1999). Bourdieu. A Critical reader. London: Blackwell.

Simonson et al (2013). The history of communication history. In Simonson et al (2013).: The handbook of communication history. London: Routledge. 13-58.

Thatcher, J., Ingram, N., Burke, C. \& Abrahams, J. (2016). Bourdieu: The next generation. the development of Bourdieu's intellectual heritage in contemporary UK sociology. London: Routledge.

Thomas-Slayter, B. (2003). Southern exposure: international development and the Global South in the twenty-first century. Bloomfield: Kumarian Press.

Wacquant, L. (2018). Bourdieu comes to town: Pertinence, principles, applications. International Journal of Urban and Regional Research, 42(1), 90-105. CrossRef

Waisbord, S. (2015a). My vision for the Journal of Communication. Journal of Communication, 65, 585-588. CrossRef

Waisbord, S. (2015b). Three challenges for communication and global social change. Communication Theory 25, 144-165. CrossRef

Waisbord, S. \& Mellado, C. (2014). De-westernizing communication studies: A reassessment. Communication Theory, 24, 361-372. $\underline{\text { CrossRef }}$

Wang, G. (2014). Culture, paradigm, and communication theory: a matter of boundary or commensurability? Communication Theory, 24, 373-393. CrossRef 
Wiedemann, T. \& Meyen, M. (2016). Internationalization through Americanization: The expansion of the International Communication Association's leadership to the world. International Journal of Communication, 10, 1489-1509.

Yutisri, P. (2016). The Publishing Industry in Thailand. Publishing Research Quarterly, 32, 261-265. CrossRef

Zelizer, B. (2015). Making communication theory matter. Communication Theory, 25, 410415. $\underline{\text { CrossRef }}$ 